\title{
Resistance training and cardiovascular autonomic modulation in humans: a systematic review and meta-analysis
}

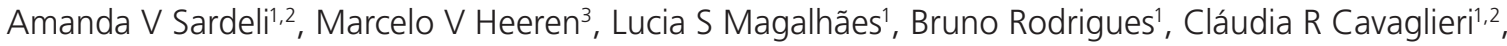 \\ Mara Patrícia T Chacon-Mikahil',2.
}

\begin{abstract}
Background. Studies investigating resistance training (RT) effects on cardiovascular autonomic modulation (CAM) have shown controversial results. Objective. To address the effect of RT on CAM in humans, in healthy and unhealthy individuals by analysing the findings of previous studies. Methods. An updated search (MEDLINE on January 18, 2016) found 19 studies testing the basal heart rate variability (HRV) before and after a RT intervention in humans. Results. Although, some individual studies showed significant effects from RT on HRV in both directions, the overall effect (standard difference in means) was not significantly on all HRV parameters analysed (time and frequency domains). No RT subgroup (samples and protocols features) presented significant effect on sympathovagal balance, limiting the comprehension about these variations. Conclusion. We conclude RT does not change humans CAM.

Keywords: Exercise; Resistance Training; Strength Training; Autonomic Nervous System; Cardiovascular System; Herat Rate Variability.
\end{abstract}

\section{BACKGROUND}

The cardiovascular diseases represent $30 \%$ of all causes of deaths in the world. The normal heart function maintenance is achieved through various mechanisms among these, cardiovascular neural regulation, encompassing the sympathetic and parasympathetic autonomic nervous system regulation ${ }^{(1)}$. As such, the assessment of cardiovascular autonomic modulation (CAM), by direct or indirect methods, has been used as an important tool on the clinical and research scene in order to provide information that may contribute to understanding of the cardiovascular complications.

Heart rate variability (HRV) is recognized as an indicator of CAM and it is an independent predictor of mortality in individuals free of cardiovascular diseases, in patients after myocardial infarction, with sudden death risk, congestive heart failure and individuals with diabetes mellitus ${ }^{(2-6)}$. Additionally, HRV is reduced with aging ${ }^{(7)}$, hypertension ${ }^{(8)}$ and can be favorable modulated following exercise training period ${ }^{(9)}$.

Regarding the exercise training benefits on CAM, several studies have demonstrated such positive changes through endurance-training. In fact, beneficial impacts of endurance-training on HRV have been seeing in diverse health conditions, ages and physical condition basal level(10). The benefits in HRV through exercise training could be due to many factors including higher neuronal activity, improved baroreflex sensitivity, increase in vasoactive factors concentration and improvements in endothelial function ${ }^{(11,12)}$. Otherwise, the resistance training (RT) effects on HRV are quite controversial. Many studies have shown null effect on $H_{R V}{ }^{(13-15)}$, while negative effect has also been observed ${ }^{(16)}$, as well as, more recently studies have demonstrated benefic effects from RT on HRV in people with some diseases such as hypertension and Chronic obstructive pulmonary disease $(\mathrm{COPD})^{(17,18)}$.

It is possible the belief about the negative effects of RT on CAM lies in the fact that this training may increase the sympathetic outflow for heart and blood vessels ${ }^{(19,20)}$, increasing electric instability and myocardial contraction strength as well as the sudden death risks ${ }^{(21)}$. Furthermore, at high intensity, a traditional RT session may leads to CAM imbalance ${ }^{(19)}$ and lasts longer time to complete recovery when compared to traditional endurance-exercise ${ }^{(22)}$, which might explain divergent chronic effects.

Corresponding Author: Amanda Veiga Sardeli, Laboratory of Exercise Physiology - FISEX, Faculty of Physical Education, University of Campinas, Av. Érico Veríssimo, 701 CEP 13083-851, PO Box 6134, Campinas, Brazil, Tel +55 193521 6625, e-mail: amandaveigasardeli@yahoo.com.br.

${ }^{1}$ Laboratory of Exercise Physiology - FISEX, Faculty of Physical Education, Universidade Estadual de Campinas (UNICAMP), Campinas - SP, Brazil

2 Faculty of Medical Sciences, Universidade Estadual de Campinas (UNICAMP), Campinas - SP, Brazil

Full list of author information is available at the end of the article.

Non-financial competing interests: There is no financial competing interest among the authors.

Submission date 03 November 2017; Acceptance date 28 December 2017; Publication date 14 February 2018 
Although, several RT protocols effects have been tested on HRV in populations who are diverse in age and health condition, the literature lacks a consensus about RT effects in humans HRV. The samples and RT protocols features need to be analysed as confounder factors to address the RT contribution to CAM in different populations, identifying how the RT protocol variables should be modulated to reach the target effects. Thus, this study consists of a systematic review with meta-analysis on the RT influence on HRV parameters, from young to elderly, in healthy and unhealthy individuals by analysing the findings of previous studies.

\section{METHODS}

\section{Search Strategy, Study Selection and Eligibility Criteria}

We searched the electronic database MEDLINE (accessed by PubMed) on January 18, 2016 (see the Figure 1 in Supplementary material). The initial search comprised the terms heart rate variability, exercise, resistance and strength training, and related entry terms. Our inclusion criteria were: a) HRV measurements at rest in the supine or in seated position; b) HRV measurements before and after at least 4 weeks of RT; c) from young to elderly of any gender and healthy condition. Our exclusion criteria were: a) animal studies; b) not written in English language; c) training interventions with other type of exercises besides RT; d) not presenting numeric values for the meta-analysis.

\section{Data Extraction}

Titles and retrieved articles abstracts were independently evaluated by two investigators (AVS). The investigators were not blinded to authors, institutions and journals. The abstracts which did not provide enough information regarding the inclusion and exclusion criteria were retrieved for full text evaluation. Investigators independently evaluated full-text articles and determined eligibility studies.

\section{Assessment of Risk of Bias}

We assessed the methods quality studies using the PEDro scale. We opted to null the questions regarding patient and care provider to be blinded as it is impossible considering exercise interventions. Thus, scores on the PEDro scale range from 0 (very low methodologic quality) to 9 (high methodological quality). Methodologic quality was not an inclusion criterion of this review however they are detailed in an additional table file (see Table 1 in Supplementary material).

\section{Heart Rate Variability measurements}

Alterations in the R-R interval duration assigned as HRV are normal and expected. Since it is a periodic variable, the HRV can be analysed according to time or frequency domains. The time domain analysis is applied through statistical indexes calculated by a mathematical formula based on the RR interval direct measurement or based on the differences between the adjacent intervals (SDNN, RMSSD) ${ }^{(23)}$. The frequency domain analysis (spectral analysis) is based on the identification through mathematic models (Fast Fourier Transform or autoregressive model) of several cardiac cycles oscillation frequency ranges ${ }^{(23)}$. The most studied are the low and high frequency bands representing sympathetic and parasympathetic modulation indexes respectively. They are determined by complex hemodynamic, electrophysiological, and humoral interactions as well as by the autonomic and central nervous system regulation ${ }^{(23)}$.

\section{Statistical Analysis}

We analysed the HRV parameters most investigated in the studies: the RR interval (RRi); the root mean square standard deviation (RMSSD); the standard deviation of all RR normal intervals (SDNN); high frequency domain (HF) and the normalized units of low frequency domain (LF); and the sympathovagal balance (LF/HF) ${ }^{(23)}$. All metaanalyses were performed using Comprehensive MetaAnalysis (CMA) software, version 3.3.070. The effect size was calculated based on standard mean difference, considering: 1) change from pre to post interventions mean difference between training and control groups; and 2) change from pre to post interventions when there was not control group at the study. Since there was no statistical significance for heterogeneity we opted for the fixed effects model. When we had independent subgroups within a study, each subgroup was treated as a separate study. We assumed a conservative pre-post correlation of $0.5^{(24)}$.

\section{RESULTS}

Table 2 (see Supplementary material) shows the characteristics of the 19 studies reviewed herein, which were published between 1996 and 2015. The mean score of the studies evaluated through Pedro Scale were 6 (Table 1, Supplementary material). A separate meta-analysis was performed for the following HRV indexes: RRi (7 RT trials), RMSSD (9 RT trials), SDNN (8 RT trials), HF (20 RT trials), LF (19 RT trials) and LF/HF (14 RT trials). Among all time and frequency domain index analysed, RT presented no significant effect on HRV (Figure 1, 2 and 3). Most analyses showed an $I^{2}$ equal to zero; however LF/HF meta-analysis showed an $I^{2}$ of $35 \%$, which enable us to conduct subgroup analysis. The LF/HF subgroup analysis showed no differences between the subgroups analysed, excepting for weekly frequency equal or lower than 2 days significant increased LF/HF (see Table 3 in Supplementary material). 
A

\begin{tabular}{|c|c|c|c|c|c|}
\hline Study name & Subgroup & $\begin{array}{l}\text { Std diff } \\
\text { in means }\end{array}$ & $\begin{array}{l}\text { Standard } \\
\text { error }\end{array}$ & p-Value & $\begin{array}{l}\text { Relative } \\
\text { weight }\end{array}$ \\
\hline Cooke, 2005 & & 0.055 & 0.428 & 0.897 & $6.60 \%$ \\
\hline Gerage, 2013 & & 0.158 & 0.372 & 0.671 & $8.74 \%$ \\
\hline Heffernan, 2007 & & 0.185 & 0.270 & 0.493 & $16.67 \%$ \\
\hline Heffernan, 2009 & african & 0.030 & 0.236 & 0.899 & $21.79 \%$ \\
\hline Heffernan, 2009 & white & 0.122 & 0.209 & 0.561 & $27.65 \%$ \\
\hline Piras, 2015 & & 0.581 & 0.342 & 0.089 & $10.37 \%$ \\
\hline Selig, 2004 & & 0.027 & 0.385 & 0.945 & $8.16 \%$ \\
\hline \multicolumn{2}{|c|}{ Sumarized fixed effect } & 0.151 & 0.110 & 0.171 & \multirow[t]{2}{*}{$100 \%$} \\
\hline $\begin{array}{l}\text { Heterogeneity } \\
\text { Test for overa }\end{array}$ & $=0.00 ; \mathrm{Q}$ & $\begin{array}{l}3 ; \mathrm{df}=6.0 \\
=0.17)\end{array}$ & $.91) ; \mathrm{I}^{2}$ & $0 \%$ & \\
\hline
\end{tabular}

\section{B}

\begin{tabular}{|c|c|c|c|c|c|}
\hline Study name & Subgroup & $\begin{array}{l}\text { Std diff } \\
\text { in means }\end{array}$ & $\begin{array}{l}\text { Standard } \\
\text { error }\end{array}$ & p-Value & $\begin{array}{l}\text { Relative } \\
\text { weight }\end{array}$ \\
\hline Gavi, 2014 & & -0.334 & 0.248 & 0.178 & $15.56 \%$ \\
\hline Gerage, 2013 & & 0.138 & 0.372 & 0.711 & $6.93 \%$ \\
\hline Heffernan, 2009 & african & 0.202 & 0.238 & 0.396 & $16.93 \%$ \\
\hline Heffernan, 2009 & white & 0.135 & 0.209 & 0.521 & $21.88 \%$ \\
\hline Madden, 2006 & & 0.227 & 0.379 & 0.550 & $6.68 \%$ \\
\hline Millar, 2013 & & -0.248 & 0.422 & 0.557 & $5.38 \%$ \\
\hline Piras, 2015 & & 0.311 & 0.324 & 0.337 & $9.15 \%$ \\
\hline Ricci-Vitor, 2013 & & 0.507 & 0.295 & 0.085 & $11.05 \%$ \\
\hline Selig, 2004 & & 0.228 & 0.386 & 0.555 & $6.43 \%$ \\
\hline Sumarized fixed & fect & 0.122 & 0.098 & 0.212 & $100 \%$ \\
\hline \multicolumn{5}{|c|}{$\begin{array}{l}\text { Heterogeneity: } \mathrm{Tau}^{2}=0.00 ; \mathrm{Q}=6.46 ; \mathrm{df}=8.00(\mathrm{p}=0.59) ; \mathrm{I}^{2}=0.00 \% \\
\text { Test for overall effect: } \mathrm{Z}=1.24(\mathrm{p}=0.21)\end{array}$} & \\
\hline
\end{tabular}

C

\begin{tabular}{lllll} 
Study name & $\begin{array}{l}\text { Std diff } \\
\text { in means }\end{array}$ & $\begin{array}{l}\text { Standard } \\
\text { error }\end{array}$ & p-Value & $\begin{array}{l}\text { Relative } \\
\text { weight }\end{array}$ \\
Allen, 2003 & -0.134 & 0.318 & 0.674 & $15.65 \%$ \\
Gerage, 2013 & 0.000 & 0.372 & 1.000 & $11.44 \%$ \\
Madden, 2006 & -0.131 & 0.378 & 0.729 & $11.03 \%$ \\
Millar, 2013 & 0.152 & 0.421 & 0.718 & $8.90 \%$ \\
Piras, 2015 & 0.406 & 0.329 & 0.217 & $14.59 \%$ \\
Ricci-Vitor, 2013 & 0.632 & 0.304 & 0.037 & $17.11 \%$ \\
Selig, 2004 & -0.081 & 0.385 & 0.834 & $10.64 \%$ \\
Wanderley, 2013 & -0.541 & 0.385 & 0.160 & $10.64 \%$ \\
Sumarized fixed effect & 0.079 & 0.126 & 0.528 & $100 \%$ \\
\begin{tabular}{|l} 
Heterogeneity: Tau ${ }^{2}=0.01 ; \mathrm{Q}=7.89 ; \mathrm{df}=7.00(\mathrm{p}=0.34) ; \mathrm{I}^{2}=11.35 \%$ \\
Test for overall effect: $\mathrm{Z}=0.63(\mathrm{p}=0.52)$
\end{tabular} & & $-\mathbf{1 . 5 0}$ \\
\hline
\end{tabular}

Figure 1. Forest plots of the effect of resistance training on time domain index. A:RR interval; B: the root mean square standard deviation (RMSSD); C: standard deviation of all RR normal intervals (SDNN).

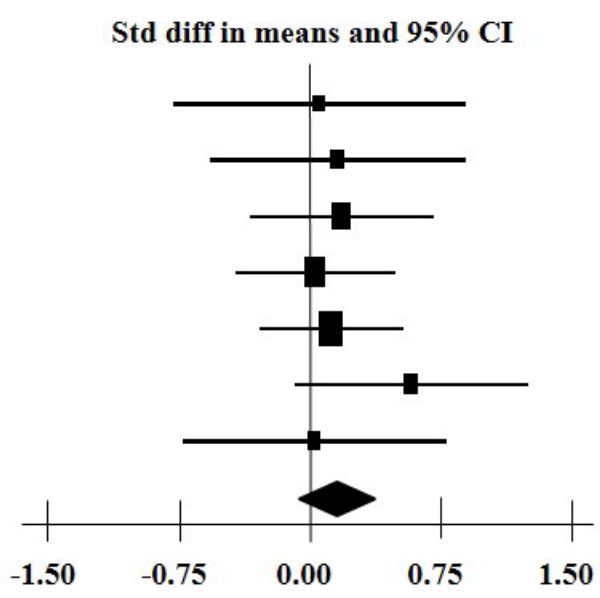

Std diff in means and $95 \% \mathrm{CI}$

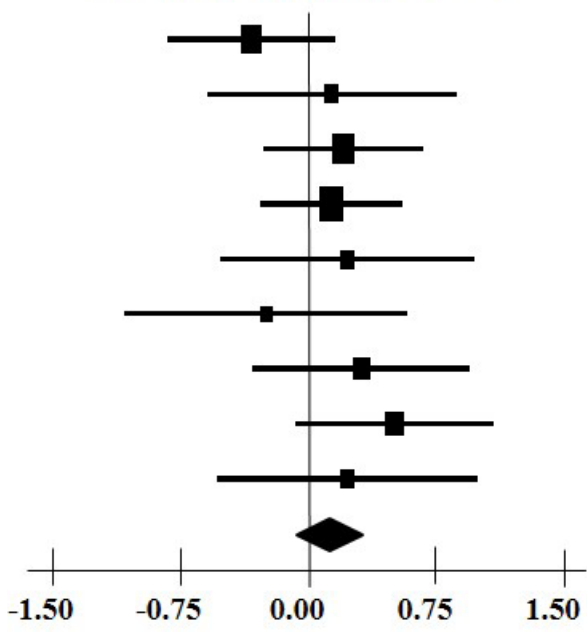

Std diff in means and $95 \%$ CI

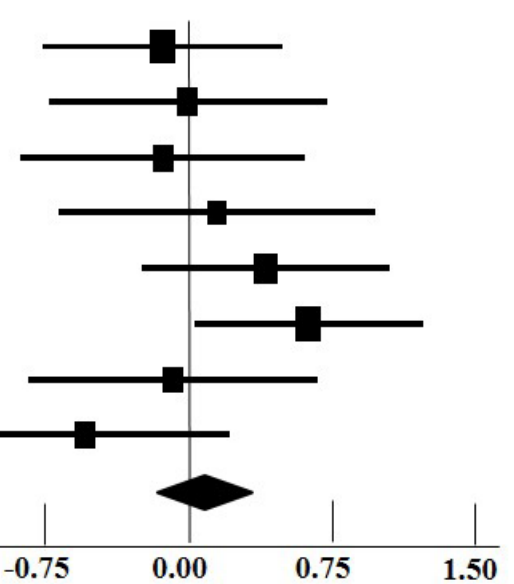


A

\begin{tabular}{llclll} 
Study name & Subgroup & $\begin{array}{l}\text { Std diff } \\
\text { in means }\end{array}$ & $\begin{array}{l}\text { Standard } \\
\text { error }\end{array}$ & $\begin{array}{l}\text { p-Value } \\
\text { Allen, 2003 }\end{array}$ & $\begin{array}{c}\text { Relative } \\
\text { weight }\end{array}$ \\
Collier, 2009 & -0.164 & 0.318 & 0.606 & $4.71 \%$ \\
Cooke, 2005 & 0.230 & 0.258 & 0.858 & $7.15 \%$ \\
Forte, 2003 & high intensity & 0.240 & 0.321 & 0.454 & $4.64 \%$ \\
Forte, 2003 & low intensity & -0.472 & 0.333 & 0.157 & $4.29 \%$ \\
Gavi, 2014 & & 0.109 & 0.247 & 0.660 & $7.83 \%$ \\
Gerage, 2013 & 0.072 & 0.372 & 0.847 & $3.45 \%$ \\
Heffernan, 2007 & & -0.058 & 0.267 & 0.827 & $6.67 \%$ \\
Heffernan, 2009 & african & 0.066 & 0.236 & 0.779 & $8.57 \%$ \\
Heffernan, 2009 & white & -0.147 & 0.210 & 0.483 & $10.85 \%$ \\
Karavirta, 2009 & & -0.177 & 0.321 & 0.581 & $4.64 \%$ \\
Kingsley, 2010 & & 0.000 & 0.224 & 1.000 & $9.54 \%$ \\
Madden, 2006 & & 0.122 & 0.378 & 0.746 & $3.33 \%$ \\
Melo, 2008 & -0.786 & 0.381 & 0.039 & $3.28 \%$ \\
Millar, 2013 & & 0.192 & 0.422 & 0.649 & $2.68 \%$ \\
Piras, 2015 & & 0.135 & 0.318 & 0.670 & $4.73 \%$ \\
Selig, 2004 & & 0.328 & 0.388 & 0.398 & $3.17 \%$ \\
Taylor, 2003 & & 0.260 & 0.529 & 0.624 & $1.70 \%$ \\
Van Hoof, 1996 & & 0.576 & 0.409 & 0.158 & $2.86 \%$ \\
Wanderley, 2013 & & 0.004 & 0.379 & 0.992 & $3.32 \%$ \\
Sumarized fixed effect & & 0.011 & 0.069 & 0.872 & $100 \%$ \\
\hline Heterogeneity: Tau ${ }^{2}=0.00 ; \mathrm{Q}=11.96 ; \mathrm{df}=19.00(\mathrm{p}=0.88) ; \mathrm{I}^{2}=0.00 \%$ & & \\
Test for overall effect: $\mathrm{Z}=0.16(\mathrm{p}=0.87)$ & & & & \\
\hline
\end{tabular}

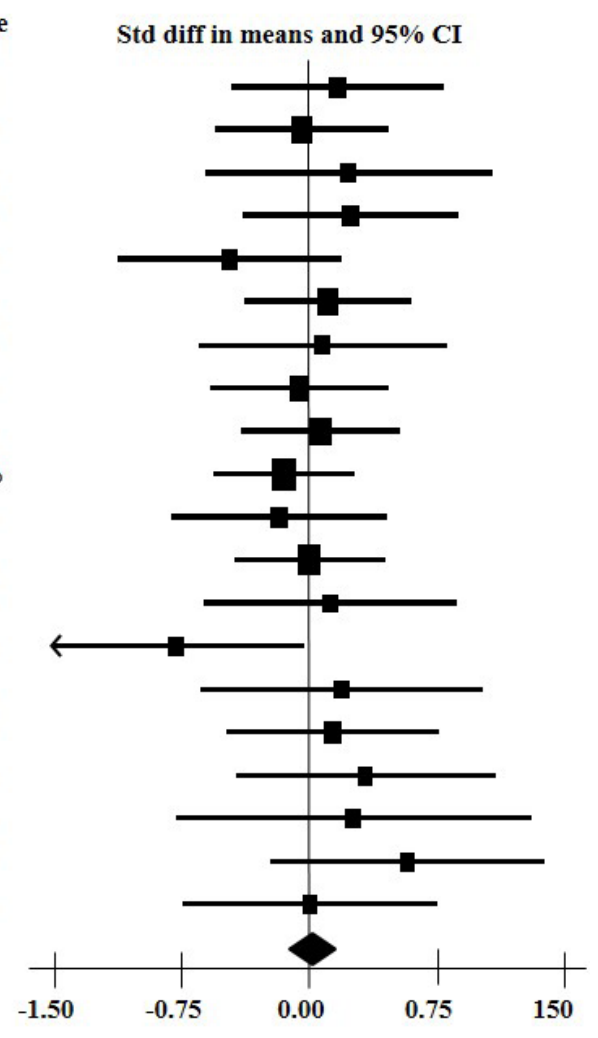

B

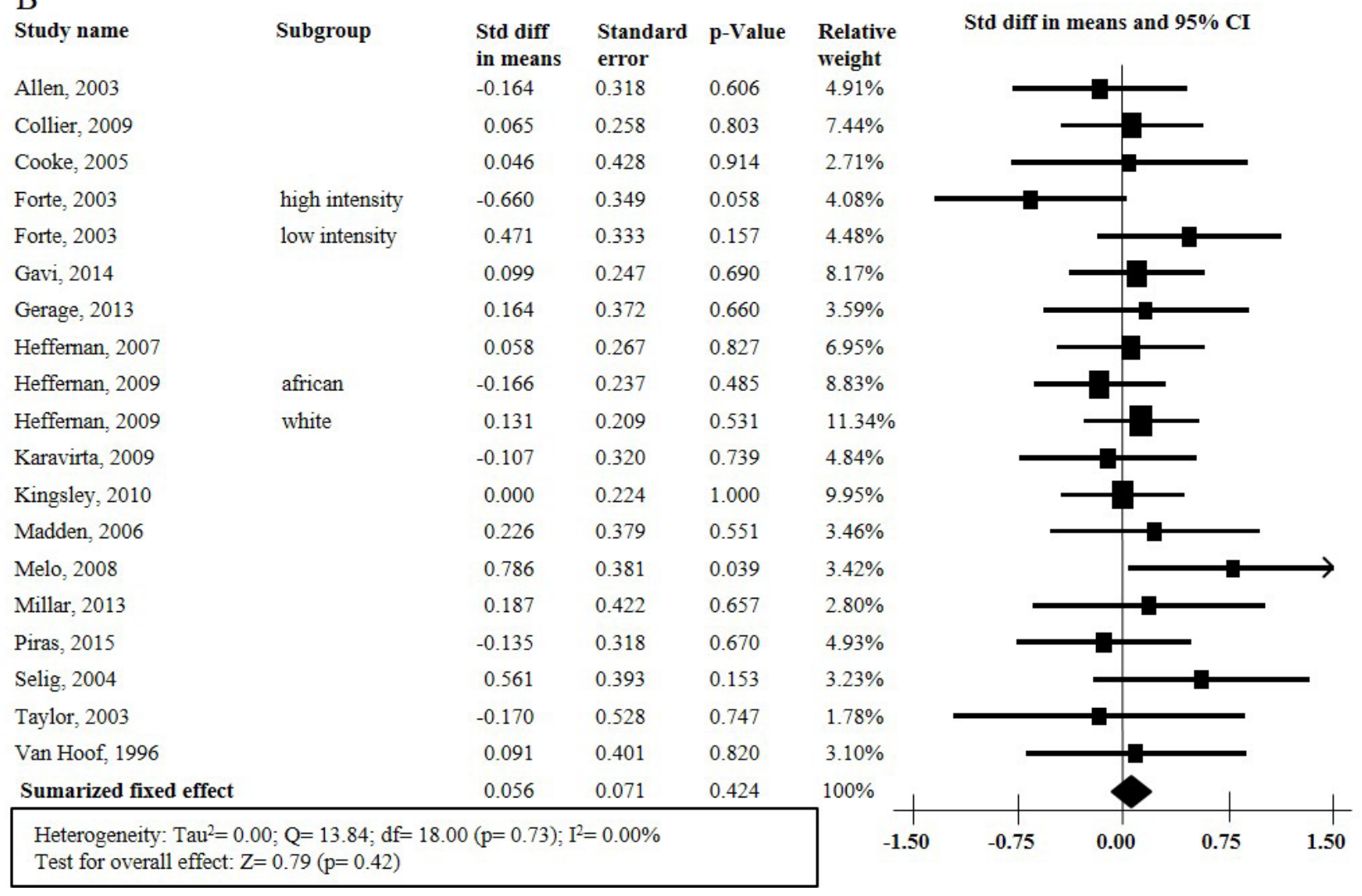

Figure 2. Forest plots of the effect of resistance training on frequency domain indexes. A: High frequency domain (HF); B: Low frequency domain (LF). 
LF/HF

\begin{tabular}{|c|c|c|c|c|}
\hline Study name & Subgroup & $\begin{array}{l}\text { Std diff } \\
\text { in means }\end{array}$ & $\begin{array}{l}\text { Standard } \\
\text { error }\end{array}$ & p-Value \\
\hline Collier, 2009 & & 0.372 & 0.267 & 0.163 \\
\hline Forte, 2003 & high intensity & -0.794 & 0.363 & 0.029 \\
\hline Forte, 2003 & low intensity & 0.454 & 0.332 & 0.172 \\
\hline Gavi, 2014 & & 0.477 & 0.250 & 0.056 \\
\hline Gerage, 2013 & & -0.050 & 0.372 & 0.893 \\
\hline Heffernan, 2007 & & 0.208 & 0.270 & 0.441 \\
\hline Heffernan, 2009 & african & -0.169 & 0.237 & 0.476 \\
\hline Heffernan, 2009 & white & 0.063 & 0.209 & 0.764 \\
\hline Kingsley, 2010 & & 0.311 & 0.324 & 0.337 \\
\hline Melo, 2008 & & 0.614 & 0.363 & 0.091 \\
\hline Millar, 2013 & & -0.333 & 0.423 & 0.432 \\
\hline Piras, 2015 & & -0.175 & 0.319 & 0.584 \\
\hline Selig, 2004 & & -0.624 & 0.394 & 0.114 \\
\hline Taylor, 2003 & & -0.290 & 0.530 & 0.584 \\
\hline Sumarized fixed effect & & 0.072 & 0.081 & 0.377 \\
\hline
\end{tabular}

Figure 3. Forest plot of the effect of resistance training on sympathovagal balance (LF/HF).

\section{DISCUSSION}

This study aimed to determine the RT effect on CAM in humans and our main finding was RT does not change the general population CAM. Many factors would justify these findings such as sample features, training protocols and type of HRV measurements. Although there was not statistical significance for the difference among these features a discursive explanation is indispensable.

Observing the effect of each study, HRV maintenance following RT interventions were evidenced in young, middleaged and elderly; in men and women; in normal weight, overweight and obese; in healthy and unhealthy individuals.

In addition, some researchers suggest that individuals beginning training intervention with higher HRV compared to the sedentary ones might reach smaller magnitudes of adaptation ${ }^{(25-28)}$. Regarding the results of original studies reviewed, two of them with COPD or hypertensive individuals samples really showed benefits over HRV parameters after RT intervention ${ }^{(17,29)}$. Nevertheless, the subgroup analysis showed the effect size in unhealthy group was very small and not significantly different of the healthy group.
HRV may be changed depending on volume and intensity protocol, as seeing higher volumes and/or intensities of endurance training improved $\mathrm{CAM}^{(30,31)}$. Forte et al. ${ }^{(32)}$ compared the different RT intensities effects on HRV however none of the training protocols were able to change the HRV parameters.

RT protocols are composed of dynamic and static components. The dynamic component affects the cardiovascular system in a different fashion to the static component $^{(33)}$, and the magnitude of participation of each component diverge among RT protocols. Despite the known static component influence on huge increases in sympathetic outflow ${ }^{(34-36)}$, it is not clearly if the acute post exercise changes magnitude could explain the chronic RT effects. Nevertheless, in the present study, subgroup analysis showed the diverse durations, volumes or intensities applied were not able to differentiate cardiovascular autonomic adaptations (Table 3, in Supplementary material). We believe the difference found in weekly frequency was a coincidence, since we have gotten the low number studies within this category leading to high homogeneity (Table 3, in Supplementary material). 
The mechanisms leading to CAM changes with exercise training are not completely elucidated however some good candidates have been identified especially regarding endurance exercise training. The benefits of exercise training in CAM could be due to many factors, including increased neuronal activity or plasticity in the cardiovascular control center, increased central arterial compliance that improves baroreflex sensitivity, reduced angiotensin II and renin, decreased catecholamine levels, decreased beta-adrenergic receptor density or improved endothelial function and oxide nitric availability with exercise training ${ }^{(11,12,37,38)}$. Whether endurance training prompt different effects compared to RT, it is quite difficult to identify among all the causes of these adaptations, the ones that should not happen following RT. However, the increase in central arterial stiffness following $\mathrm{RT}^{(39)}$, might explain at least part of the divergent results between exercise training types, since it reduces baroreflex sensitivity ${ }^{(11)}$. Since nervous system is complex and interact with the other systems we guess several mechanisms related to HRV and exercise stills unknown.

A limitation of this study was the absence of heterogeneity between studies which is controversial. The variance for cardiovascular autonomic adaptations through exercise is high among individuals leading to higher heterogeneity within studies limiting the appearance between studies differences.

\section{CONCLUSION}

RT is already known to promote diverse cardiovascular adaptations in healthy and unhealthy individuals. Nevertheless, when the cardiovascular health is assessed by HRV parameters, the RT is unable to induce adaptations in the traditional time and frequency domain analyses, in the whole population investigated. Thus, based on the present systematic review and meta-analysis, we conclude RT can be prescribed for health purposes without affect CAM in humans. Moreover, since human cardiovascular autonomic adaptation following RT is widely heterogeneous further studies and reviews are needed to enrich and confirm this finding in the future.

\section{AUTHOR'S CONTRIBUTION}

AVS, MVH, LSM, CRC and MPTC developed the design. AVS, MVH and LSM carried out the data collection. AVS performed data analysis. AVS, MVH, LSM and BR conceived the manuscript that was reviewed for CRC and MPTC.

\section{COMPETING INTERESTS}

The author(s) declare that they have no competing interests.

\section{AUTHOR DETAILS}

${ }^{3}$ Education Department, Instituto Federal de Educação, Ciência e Tecnologia (IFSP), Catanduva - SP, Brazil

\section{REFERENCES}

1. Mancia G, Frattola A, Groppelli A, Omboni S, Parati G, Ulian L, et al. Blood pressure reduction and end-organ damage in hypertension. Journal of hypertension Supplement: official journal of the International Society of Hypertension. 1994;12:S35-41.

2. Shankar A, Mitchell P, Rochtchina E, Wang JJ. The association between circulating white blood cell count, triglyceride level and cardiovascular and all-cause mortality: population-based cohort study. Atherosclerosis. 2007;192:177-83.

3. TFotESo. Heart rate variability. Standards of measurement, physiological interpretation, and clinical use. Task Force of the European Society of Cardiology and the North American Society of Pacing and Electrophysiology. European heart journal. 1996;17:354-81.

4. Malliani A, Lombardi F, Pagani M. Power spectrum analysis of heart rate variability: a tool to explore neural regulatory mechanisms. $\mathrm{Br}$ Heart J. 1994;71:1-2

5. Nolan J, Batin PD, Andrews R, Lindsay SJ, Brooksby P, Mullen M, et al. Prospective study of heart rate variability and mortality in chronic heart failure: results of the United Kingdom heart failure evaluation and assessment of risk trial (UK-heart). Circulation. 1998;98:1510-6.

6. O'Brien IA, McFadden JP, Corrall RJ. The influence of autonomic neuropathy on mortality in insulin-dependent diabetes. Q J Med. 1991;79:495-502.

7. Jensen-Urstad K, Storck N, Bouvier F, Ericson M, Lindblad LE, Jensen-Urstad $M$. Heart rate variability in healthy subjects is related to age and gender. Acta physiologica Scandinavica. 1997;160:235-41.

8. Singh JP, Larson MG, Tsuji H, Evans JC, O’Donnell CJ, Levy D. Reduced heart rate variability and new-onset hypertension: insights into pathogenesis of hypertension: the Framingham Heart Study. Hypertension. 1998;32:293-7.

9. van Lien R, Goedhart A, Kupper N, Boomsma D, Willemsen G, de Geus EJ. Underestimation of cardiac vagal control in regular exercisers by 24-hour heart rate variability recordings. International journal of psychophysiology: official journal of the International Organization of Psychophysiology. 2011;81:169-76.

10. Carter JB, Banister EW, Blaber AP. The effect of age and gender on heart rate variability after endurance training. Medicine and science in sports and exercise. 2003;35:1333-40.

11. Masson GS, Costa TS, Yshii L, Fernandes DC, Soares PP, Laurindo $F R$, et al. Time-dependent effects of training on cardiovascular control in spontaneously hypertensive rats: role for brain oxidative stress and inflammation and baroreflex sensitivity. PloS one. 2014;9:e94927.

12. Golbidi S, Laher I. Molecular mechanisms in exercise-induced cardioprotection. Cardiology research and practice. 2011;2011:972807.

13. Wanderley FA, Moreira A, Sokhatska O, Palmares C, Moreira P, Sandercock $\mathrm{G}$, et al. Differential responses of adiposity, inflammation and autonomic function to aerobic versus resistance training in older adults. Exp Gerontol. 2013;48:326-33.

14. Gavi MB, Vassalo DV, Amaral FT, Macedo DC, Gava PL, Dantas EM, et al. Strengthening exercises improve symptoms and quality of life but do not change autonomic modulation in fibromyalgia: a randomized clinical trial. PloS one. 2014;9:e90767.

15. Kingsley JD, McMillan V, Figueroa A. The effects of 12 weeks of resistance exercise training on disease severity and autonomic modulation at rest and after acute leg resistance exercise in women with fibromyalgia. Archives of physical medicine and rehabilitation. 2010;91:1551-7.

16. Melo RC, Quiterio RJ, Takahashi AC, Silva E, Martins LE, Catai AM. High eccentric strength training reduces heart rate variability in healthy older men. British journal of sports medicine. 2008;42:59-63.

17. Ricci-Vitor AL, Bonfim R, Fosco LC, Bertolini GN, Ramos EM, Ramos D, et al. Influence of the resistance training on heart rate variability, functional capacity and muscle strength in the chronic obstructive pulmonary disease. European journal of physical and rehabilitation medicine. 2013;49:793-801. 
18. Millar PJ, Levy AS, McGowan CL, McCartney N, MacDonald MJ. Isometric handgrip training lowers blood pressure and increases heart rate complexity in medicated hypertensive patients. Scand J Med Sci Sports. 2013;23:620-6.

19. Heffernan KS, Kelly EE, Collier SR, Fernhall B. Cardiac autonomic modulation during recovery from acute endurance versus resistance exercise. European journal of cardiovascular prevention and rehabilitation: official journal of the European Society of Cardiology, Working Groups on Epidemiology \& Prevention and Cardiac Rehabilitation and Exercise Physiology. 2006;13:80-6.

20. Rezk CC, Marrache RC, Tinucci T, Mion D, Jr., Forjaz CL. Post-resistance exercise hypotension, hemodynamics, and heart rate variability: influence of exercise intensity. European journal of applied physiology. 2006;98:10512.

21. Albert CM, Mittleman MA, Chae CU, Lee IM, Hennekens $\mathrm{CH}$, Manson JE. Triggering of sudden death from cardiac causes by vigorous exertion. The New England journal of medicine. 2000;343:1355-61.

22. Stanley J, Peake JM, Buchheit M. Cardiac parasympathetic reactivation following exercise: implications for training prescription. Sports medicine. 2013;43:1259-77.

23. TaskForce. Heart rate variability. Standards of measurement, physiological interpretation, and clinical use. Task Force of the European Society of Cardiology and the North American Society of Pacing and Electrophysiology. Eur Heart J. 1996;17:354-81.

24. Boreinstein M, Hedges L, Higgins J, Rothstein H. Introduction to metaanalysis. Wiley; 2009.

25. Aslani A, Aslani A, Kheirkhah J, Sobhani V. Cardio-pulmonary fitness test by ultra-short heart rate variability. J Cardiovasc Dis Res. 2011;2:233-6.

26. Christoforidi V, Koutlianos N, Deligiannis P, Kouidi E, Deligiannis A. Heart rate variability in free diving athletes. Clinical physiology and functional imaging. 2012;32:162-6.

27. Soares-Miranda L, Negrao CE, Antunes-Correa LM, Nobre TS, Silva P, Santos $\mathrm{R}$, et al. High levels of C-reactive protein are associated with reduced vagal modulation and low physical activity in young adults. Scand J Med Sci Sports. 2012;22:278-84.
28. Soares-Miranda L, Sandercock G, Vale S, Silva P, Moreira C, Santos R, et al. Benefits of achieving vigorous as well as moderate physical activity recommendations: evidence from heart rate complexity and cardiac vagal modulation. Journal of sports sciences. 2011;29:1011-8.

29. Taylor AC, McCartney N, Kamath MV, Wiley RL. Isometric training lowers resting blood pressure and modulates autonomic control. Medicine and science in sports and exercise. 2003;35:251-6.

30. Bonaduce D, Petretta M, Cavallaro V, Apicella C, lanniciello A, Romano $\mathrm{M}$, et al. Intensive training and cardiac autonomic control in high level athletes. Medicine and science in sports and exercise. 1998;30:691-6.

31. Buchheit M, Simon C, Charloux A, Doutreleau S, Piquard F, Brandenberger G. Heart rate variability and intensity of habitual physical activity in middleaged persons. Medicine and science in sports and exercise. 2005;37:1530-4.

32. Forte R, De Vito G, Figura F. Effects of dynamic resistance training on heart rate variability in healthy older women. European journal of applied physiology. 2003;89:85-9.

33. Lind AR, McNicol GW. Muscular factors which determine the cardiovascular responses to sustained and rhythmic exercise. Canadian Medical Association journal. 1967;96:706-15.

34. Halliwill JR, Taylor JA, Eckberg DL. Impaired sympathetic vascular regulation in humans after acute dynamic exercise. J Physiol. 1996;495 (Pt 1):279-88.

35. Pratley R, Nicklas B, Rubin M, Miller J, Smith A, Smith M, et al. Strength training increases resting metabolic rate and norepinephrine levels in healthy 50- to 65-yr-old men. J Appl Physiol (1985). 1994;76:133-7.

36. Seals DR. Sympathetic neural discharge and vascular resistance during exercise in humans. J Appl Physiol (1985). 1989;66:2472-8.

37. Marosi K, Mattson MP. BDNF mediates adaptive brain and body responses to energetic challenges. Trends in endocrinology and metabolism: TEM. 2014;25:89-98.

38. Routledge FS, Campbell TS, McFetridge-Durdle JA, Bacon SL. Improvements in heart rate variability with exercise therapy. The Canadian journal of cardiology. 2010;26:303-12.

39. Miyachi M, Kawano H, Sugawara J, Takahashi K, Hayashi K, Yamazaki K, et al. Unfavorable effects of resistance training on central arterial compliance: a randomized intervention study. Circulation. 2004;110:2858-63. 


\section{SUPPLEMENTARY MATERIAL}

Supplementary material accompanies this paper.

Figure 1. Studies selection flowchart.

Table 1. Quality metrics of studies according to PEDro scale questionnaire.

Table 2. Sample and RT protocol features.

Table 3. Subgroup analysis of RT effects on LF/HF.

This material is available as part of the online article from http://www.mtprehabjournal.com/. 